\title{
Intracranial Arteriovenous Malformation: Relationships between Clinical and Radiographic Factors and Cerebral Blood Flow
}

\author{
H. Hunt Batjer, Michael D. Devous, Sr.*, G. Burton SeIBerT**, \\ Phillip D. PurdY*, Ajay K. AJMANI*, Manuel Delarosa \\ and Frederick J. BONTE* \\ Division of Neurological Surgery, ${ }^{*}$ Department of Radiology, and \\ **Division of Epidemiology, the University of Texas Southwestern Medical Center \\ at Dallas, Dallas, Texas, U.S.A.
}

\begin{abstract}
Arteriovenous malformations (AVMs) dramatically alter normal cerebral circulatory dynamics. Clinical and radiographic data from 62 patients were analyzed to determine their impact on total brain blood flow (TBF) measured by single-photon emission computed tomography. $48 \%$ of patients presented with hemorrhage and $34 \%$ with progressive deficits. $37 \%$ had angiographic steal and $21 \%$ developed postoperative hyperemic complications. $40 \%$ were under 30 years old, $45 \%$ were between 30 and 50 years of age, and $15 \%$ were over 50 . TBF was less than $70 \mathrm{ml} / 100 \mathrm{gm} / \mathrm{min}$ in $32 \%$ of patients, between 70 and $84 \mathrm{ml} / 100 \mathrm{gm} / \mathrm{min}$ in $40 \%$, and greater than $84 \mathrm{ml} / 100 \mathrm{gm} / \mathrm{min}$ in $27 \%$. Female patients had higher TBF than males; $42 \%$ of females but only $17 \%$ of males had values greater than $84 \mathrm{ml} / 100 \mathrm{gm} / \mathrm{min}(\mathrm{p}<0.05)$. A trend toward decreased TBF with advancing age was noted. Intracranial hemorrhage was associated with lower TBF; $47 \%$ of patients with hemorrhage and $19 \%$ of those without had TBF of $<70 \mathrm{ml} / 100 \mathrm{gm} / \mathrm{min}(\mathrm{p}<0.05) .89 \%$ of patients with AVMs less than $5 \mathrm{~cm}$ in diameter had TBF of $\leq 84 \mathrm{ml} / 100 \mathrm{gm} / \mathrm{min}$, and $65 \%$ of those with larger AVMs had similarly low flows $(p<0.05)$. A trend toward lower TBF was observed in patients with unfavorable outcomes.
\end{abstract}

Key words: arteriovenous malformation, cerebral blood flow

\section{Introduction}

The presence of an intracranial arteriovenous malformation (AVM) dramatically influences the distribution of regional cerebral blood flow (rCBF) as well as circulatory dynamics. The high-flow, low-resistance qualities of the shunt itself can be associated with chronic hypoperfusion of adjacent brain tissue. ${ }^{22)}$ Symptoms of cerebral ischemia are well known presenting complaints of patients harboring intracranial AVMs. Detailed clinical reports appeared as early as 1949 , when Norlen ${ }^{12)}$ described improvement in a patient's hemiparesis after AVM resection. Hemodynamic characteristics of the cerebral circulation in AVM patients have been evaluated with invasive $e^{1,6,13,14,17,19)}$ as well as noninvasive tech-

\footnotetext{
Received July 4, 1988; Accepted December 1, 1988
}

niques. ${ }^{4,7,9,11,15,16,18,25,27)}$ Three-dimensional noninvasive studies using emission tomography and stable xenon-enhanced computed tomography (CT) have demonstrated evidence of hypoperfusion and flow asymmetry well within the resolution of this technology.

The present study was undertaken to determine if the clinical presentation of patients with AVMs or the radiographic features of their lesions are predictive of the magnitude of $\mathrm{CBF}$ as determined by ${ }^{133} \mathrm{Xe}$ inhalation and single-photon emission CT (SPECT). More importantly we sought to determine if preoperative CBF parameters are predictive of surgical complications or outcome.

\section{Patients and Methods}

Between 1983 and 1986, 77 patients with radio- 
graphically proven intracranial AVMs were evaluated with SPECT at the University of Texas Southwestern Medical Center campus. Sixty-two of these patients were treated in our center and form the patient base for this report. The pre- and postoperative clinical and conventional radiographic data from these invasively treated patients have been collected and analyzed. In addition to sex, age, and handedness, presenting signs and symptoms were recorded, including intracranial hemorrhage (ICH), seizures, headaches, and progressive neurological deficits.

$\mathrm{CT}$ and angiographic studies were evaluated for characteristics that might be expected to affect $\mathrm{CBF}$ patterns and surgical results. The AVM location was described as right or left hemispheric or bilateral. The angiographic diameters of the AVMs (after correction for magnification factors) were classified into three groups: less than $3 \mathrm{~cm}, 3-6 \mathrm{~cm}$, and greater than $6 \mathrm{~cm} .{ }^{21)} \mathrm{CT}$ demonstration of an intracerebral hematoma greater than $2 \mathrm{~cm}$ in diameter was noted. The number of major vessels involved was listed from one to six as follows: middle cerebral artery, anterior cerebral artery, posterior cerebral artery, vertebral artery (including the posterior inferior cerebellar artery), basilar artery (including the anterior inferior and superior cerebellar arteries), and external carotid artery. The recruitment of perforating arteries into the feeding system was noted, as was the pattern of venous drainage: superficial, deep, or both. The sum of the diameters of all angiographically visible feeding arteries was determined by direct measurement, with correction for magnification, at the point where each vessel entered the nidus. Angiographic evidence of steal was defined as a paucity of normal vessels opacified in the midarterial phase adjacent to the nidus. Redistribution phenomena, i.e., capture of both anterior cerebral artery distributions by a single carotid injection related to a frontal AVM with reversion to normal patterns after resection, were not considered evidence of steal. Perioperative hyperemic complications were liberally defined as the occurrence of unexpected or abnormal degrees of intraoperative brain swelling or hemorrhage unrelated to technical error or concealed ventricular hemorrhage. This designation also included postoperative CT evidence of edema unrelated to inadvertent proximal vascular occlusion or brain retraction as well as hemorrhage after angiographically proven complete AVM resection. The outcome was determined at the 6-month follow-up examination and rated as good (capable of independent life) or poor (not capable of independent life). Death was also listed as an outcome.
Dynamic SPECT: rCBF was determined by dynamic monitoring of the cerebral transit of ${ }^{133} \mathrm{Xe}$ with a Tomomatic 64 SPECT (Medimatic A/S, Copenhagen, Denmark), as described by Stokely et $a l^{24)}$ It consists of four detector arrays, each containing $16 \mathrm{NaI}(\mathrm{T} 1)$ scintillation crystals. The arrays are mounted in a hollow-square configuration that rotates around the subject's head at $6 \mathrm{rpm}$. Special focused collimators define three transverse tomographic cross-sections with centers $4 \mathrm{~cm}$ apart. ${ }^{133} \mathrm{Xe}$ was administered in an air/oxygen mixture (10 $\mathrm{mCi} / \mathrm{l}$ ) during the first minute of a 4-minute washin/wash-out procedure. The patient breathed room air during the remaining 3 minutes of the study, exhaling the mixture into a charcoal trap. During the 4minute measurement period, activity in the lung was monitored by a scintillation probe placed on the chest, and this activity was assumed to correspond to the arterial blood concentration of ${ }^{133} \mathrm{Xe}$ in the brain. $\mathrm{rCBF}$ was calculated in $\mathrm{ml} / 100 \mathrm{gm} / \mathrm{min}$, according to the double-integral method described by Kanno and Lassen, ${ }^{8)}$ Celsis et al.,${ }^{3)}$ and Smith et al. ${ }^{20)}$ The reproducibility and reliability of this method have been evaluated in normal subjects by Devous $e t$ al. ${ }^{5)}$ Approximately 2 minutes of adaptation time was allowed prior to initiation of the study. Each patient was asked to take a deep breath at the beginning of the study, after which no further communication occurred. The patients were positioned in the tomograph so that the three transverse cross-sections were located 2, 6, and $10 \mathrm{~cm}$ above and parallel to the canthomeatal line. Positioning was accomplished by the marking of a reference line on the face that was then aligned with the tomograph frame. These rCBF studies were obtained with the informed consent of the patients, in accordance with the policies of the Institutional Review Board of the University of Texas Southwestern Medical Center at Dallas. rCBF was not measured prior to a 3-week waiting period in patients who had suffered ICH.

Voxel flow values were displayed in a $64 \times 64$ matrix employing a 16 -shade scale that can be normalized to the highest flow value. CBF was also numerically recorded with values characterizing the entire hemisphere. Total brain blood flow (TBF) was calculated by averaging the right and left hemispheric flow values. Analysis of the data regarding rCBF patterns in this patient group included severity and distribution of hypoperfusion (steal areas) in both the ipsilateral and contralateral hemispheres. These data are presented in separate manuscripts. The present report concerns the impact of clinical and radiographic factors on TBF. Statistical significance was determined by the Chi-square test. In 
the case of small numbers in any classification category, significance was based on Fisher's exact test.

\section{Results}

\section{Clinical profile}

Twenty-five $(40 \%)$ of the patients were under 30 years of age, $28(45 \%)$ were $30-50$, and nine $(15 \%)$ were over 50 . Thirty-six (58\%) were male. While 59 patients $(95 \%)$ were right handed, 28 AVMs (45\%) were right hemispheric, $32(52 \%)$ were left hemispheric, and two $(3 \%)$ were midline or bilateral. Four AVMs were located in the posterior fossa. Nineteen $(31 \%)$ were less than $3 \mathrm{~cm}$ in diameter, 26 $(42 \%)$ were $3-6 \mathrm{~cm}$, and $17(27 \%)$ were greater than $6 \mathrm{~cm}$. Clinical symptomatology and radiographic features are presented in Table 1 . The measured sum of the diameter of each feeding vessel at its entry to the AVM nidus was less than $8 \mathrm{~mm}$ in 28 cases $(45 \%), 8-15 \mathrm{~mm}$ in $23(37 \%)$, and greater than $15 \mathrm{~mm}$ in $11(18 \%)$. Venous drainage was superficial in $30(48 \%)$, deep in $13(21 \%)$, and both in $19(31 \%)$.

Five patients $(8 \%)$ were treated only by surgical ligation of feeding vessels or intravascular embolization therapy. Definitive resection was not performed because of patients' wishes or prohibitive medical conditions. One patient died of unexpected pulmonary embolism 6 days after clipping of multiple aneurysms and ligation of middle cerebral artery vessels. All other patients underwent radiographically verified microsurgical excision. Hyperemic complications, as defined above, occurred in $13(21 \%)$. The outcome at 6 months postoperatively was good in $51(82 \%)$ and poor in four $(6 \%)$; seven patients (11\%) died.

\section{CBF patterns}

As noted above, TBF was calculated as the average of the right and left hemispheric flow values and expressed in $\mathrm{ml} / 100 \mathrm{gm} / \mathrm{min}$. Twenty patients $(32 \%)$

Table 1 Clinical profile of 62 AVM patients

\begin{tabular}{lc}
\hline \multicolumn{1}{c}{ Clinical factors } & No. of patients \\
\hline ICH & $30(48 \%)$ \\
Progressive deficit & $21(34 \%)$ \\
Seizure & $27(44 \%)$ \\
Headache & $11(18 \%)$ \\
Intracerebral hematoma $(>2 \mathrm{~cm})$ & $8(13 \%)$ \\
Angiographic steal & $23(37 \%)$ \\
Perforator involvement & $19(31 \%)$ \\
Hyperemic complications & $13(21 \%)$ \\
\hline
\end{tabular}

Table 2 Relationship of TBF to ICH

\begin{tabular}{|c|c|c|}
\hline \multirow{2}{*}{$\mathrm{TBF}(\mathrm{ml} / 100 \mathrm{gm} / \mathrm{min})$} & \multicolumn{2}{|c|}{$\mathrm{ICH}$} \\
\hline & - & + \\
\hline$<70$ & $6(19 \%)$ & $14(47 \%)$ \\
\hline $70-84$ & $17(53 \%)$ & $8(27 \%)$ \\
\hline$>84$ & $9(28 \%)$ & $8(27 \%)$ \\
\hline Total & 32 & 30 \\
\hline
\end{tabular}

had TBF of less than $70 \mathrm{ml} / 100 \mathrm{gm} / \mathrm{min}, 25(40 \%)$ had flow values of $70-84 \mathrm{ml} / 100 \mathrm{gm} / \mathrm{min}$, and 17 (27\%) had TBF of greater than $84 \mathrm{ml} / 100 \mathrm{gm} / \mathrm{min}$.

The patients' clinical characteristics had a large impact on the CBF characteristics. Female patients had significantly higher TBF values. Whereas $42 \%$ of female patients had TBF of greater than $84 \mathrm{ml} / 100$ $\mathrm{gm} / \mathrm{min}$, only $17 \%$ of males had similarly high flows $(\mathrm{p}<0.05)$. A trend was noted toward decreasing TBF with increasing age $(\mathrm{p}=0.14)$. While an even distribution over the three TBF categories was found in patients under 30 years of age, $67 \%$ of those over 50 had TBF of less than $70 \mathrm{ml} / 100 \mathrm{gm} / \mathrm{min}$. Despite the fact that ICBF was not measured within the first 3 weeks of $\mathrm{ICH}$, hemorrhagic events appeared to have a significant impact on TBF (Table 2). Among the patients who had bled, $47 \%$ had TBF of less than $70 \mathrm{ml} / 100 \mathrm{gm} / \mathrm{min}$, whereas only $19 \%$ of patients who had never bled had comparably low flow values $(p<0.05)$. A trend toward higher TBF was seen in patients who had a history of seizures, but statistical significance was not reached $(p=$ 0.11 ). No definite relationships were observed between TBF patterns and handedness of the patient, a history of headaches, or progressive neurological deficits.

Surprisingly, few radiographic features of the AVM influenced TBF. There was a tendency for larger AVMs to be associated with higher TBF, in the context of our traditional size categories: $<3$ $\mathrm{cm}, 3-6 \mathrm{~cm}$, and $>6 \mathrm{~cm}(\mathrm{p}=0.14)$. However, when AVMs were assigned only two size categories (small, $<5 \mathrm{~cm}$; large, $\geq 5 \mathrm{~cm}$ ) and $\mathrm{TBF}$ was considered simply as low $(\leq 84 \mathrm{ml} / 100 \mathrm{gm} / \mathrm{min})$ or high $(>84$ $\mathrm{ml} / 100 \mathrm{gm} / \mathrm{min}$ ), only $11 \%$ of small AVMs were associated with high TBF, while $35 \%$ of large AVMs were accompanied by high TBF $(p<0.05)$. Although a history of ICH was associated with decreased TBF, the presence of a 3-week-old or older intracerebral hematoma was not significantly correlated with TBF alterations. No statistically significant relationships were noted between TBF and the 
Table 3 Relationship of TBF to hyperemic complications

\begin{tabular}{|c|c|c|}
\hline \multirow{2}{*}{$\mathrm{TBF}(\mathrm{ml} / 100 \mathrm{gm} / \mathrm{min})$} & \multicolumn{2}{|c|}{ Hyperemic complications } \\
\hline & - & + \\
\hline$<70$ & $15(31 \%)$ & $5(38 \%)$ \\
\hline $70-84$ & $21(43 \%)$ & $4(31 \%)$ \\
\hline$>84$ & $13(27 \%)$ & $4(31 \%)$ \\
\hline Total & 49 & 13 \\
\hline
\end{tabular}

Table 4 Relationship of TBF to clinical outcome

\begin{tabular}{ccc}
\hline \multirow{2}{*}{ TBF $(\mathrm{ml} / 100 \mathrm{gm} / \mathrm{min})$} & \multicolumn{2}{c}{ Outcome } \\
\cline { 3 - 3 } & \multicolumn{1}{c}{ Good } & Poor or died \\
\cline { 2 - 3 }$<70$ & $14(27 \%)$ & $6(55 \%)$ \\
$70-84$ & $23(45 \%)$ & $2(18 \%)$ \\
$>84$ & $14(27 \%)$ & $3(27 \%)$ \\
\hline Total & 51 & 11 \\
\hline
\end{tabular}

hemisphere involved by the AVM, the number of major feeding vessels involved, the presence of perforating arteries in the feeding system, the pattern of venous drainage, the event of angiographic steal, or the sum of the diameters of all feeding arteries entering the nidus.

As shown in Table 3, the preoperative TBF values did not appear to predict the occurrence of perioperative hyperemic complications. A trend toward depression of TBF was seen in patients with unfavorable outcomes (Table 4). Six patients $(55 \%)$ who had either poor or fatal outcomes had preoperative TBF of less than $70 \mathrm{ml} / 100 \mathrm{gm} / \mathrm{min}$, while $14(27 \%)$ of those with good outcomes had TBF of less than $70 \mathrm{ml} / 100 \mathrm{gm} / \mathrm{min}(\mathrm{p}=0.16)$.

\section{Discussion}

A substantial amount of physiological data has been collected in attempts to quantitate the volume of cardiac output actually captured by intracranial AVMs as well as its impact on the cerebral circulation. Noninvasive transcranial Doppler techniques have been applied to AVM patients and marked abnormalities of blood flow and flow velocity have been detected. Schwartz and Hennerici ${ }^{18)}$ noted ipsilateral common carotid artery flow volumes of up to 600 $\mathrm{ml} / \mathrm{min}$. Lindegaard et al., ${ }^{\text {9) }}$ using transcranial methods, found flow velocities in remote arteries of $65 \mathrm{~cm} / \mathrm{sec}$ and flow velocities in actual feeding ves- sels of up to $237 \mathrm{~cm} / \mathrm{sec}$. Nornes and Grip, ${ }^{14)}$ using an intraoperative directional Doppler technique, detected flow in feeding arteries of up to $550 \mathrm{ml} / \mathrm{min}$ and total AVM flow of up to $900 \mathrm{~mL} / \mathrm{min}$. Laser Doppler velocimetry has been employed intraoperatively and has demonstrated significant increases in cortical perfusion at the time of surgical elimination of the shunt. ${ }^{17)}$ Similar findings were recently obtained by means of cortically applied thermistor/ Peltier stack arrays. ${ }^{1)}$ In these studies, mean flow values of $43 \mathrm{ml} / 100 \mathrm{gm} / \mathrm{min}$ prior to excision increased to $57 \mathrm{ml} / 100 \mathrm{gm} / \mathrm{min}$ immediately after removal of the AVM at sites remote from the AVM. The unique and varied characteristics of intracranial arteriovenous shunts are reflected by major hemodynamic derangements.

With the availability of noninvasive, three-dimensional techniques, preoperative detection of significant regions of hypoperfusion is now possible. Takeuchi et al., ${ }^{25)}$ using SPECT following intraarterial infusion of ${ }^{81 \mathrm{~m}} \mathrm{Kr}$, recently demonstrated surrounding regions of hypoperfusion in all six AVM patients studied. Using ${ }^{133} \mathrm{Xe}$ inhalation SPECT, Homan et al. ${ }^{7}$ found structurally normal brain regions to be significantly hypoperfused in eight of 11 patients studied. Flow asymmetry was also detected in the contralateral hemisphere in that study. Fourteen patients were studied by Menon and Weir ${ }^{11)}$ with ${ }^{133} \mathrm{Xe}$ inhalation and two-dimensional probe measurements, and a higher incidence of ipsilateral high flow regions and greater variability was noted in comparison to control subjects. Using stable xenon-enhanced CT CBF measurements, Okabe et al. ${ }^{15)}$ observed significant reductions in $\mathrm{CBF}$ in AVM patients compared to age-matched controls, particularly in the regions adjacent to the AVM. These authors also compared ${ }^{133} \mathrm{Xe}$ inhalation twodimensional probe measurements with stable xenonenhanced CT scans in 16 patients and concluded that, in preoperative studies, ${ }^{133} \mathrm{Xe}$ measurements overestimated cortical flow due to contamination by shunt flow. They discussed the disadvantages of two-dimensional ${ }^{133} \mathrm{Xe}$ inhalation techniques in the setting of intracranial AVM and underscored the fact that the solubility partition coefficient between blood and brain may be altered in disease states. They also mentioned errors due to scalp contamination, Compton scatter and tissue overlap. Most of these disadvantages are eliminated by three-dimensional SPECT technology. In particular, overestimates of cortical flow due to shunt contamination, scalp contamination factors, and tissue overlap are minimized with SPECT. The effect of Compton scatter is also minimized but still causes overesti- 
mates of white matter blood flow. ${ }^{5\}}$ In addition, ipsilateral TBF may be falsely elevated by inclusion of portions of the AVM in a slice. In our study the impact of this high-flow contamination may have been reduced by the fact that all patients had ipsilateral as well as contralateral areas of low flow.

Dynamic SPECT is a safe method of studying neurologically ill patients without the marked sedation produced by the doses of stable xenon that are necessary for xenon-enhanced CT studies. SPECT measurements can be readily repeated at frequent intervals during the unstable perioperative course of complicated AVM, and allows the patient to serve as his own control. rCBF data acquired from normal subjects with the same tomograph at our institution demonstrated mean gray matter flow of $72 \pm 12 \mathrm{ml} /$ $100 \mathrm{gm} / \mathrm{min}$ (mean $\pm \mathrm{SD}$ ) and individual data were reproducible in a second study. ${ }^{57}$ rCBF was higher in females than in males of all ages but statistically significant differences were detected only in the 20-29 and 30-39 age groups. rCBF declined steadily with age and showed major changes after 50 years of age. ${ }^{5)}$

In light of the results of rCBF measurements in normal controls, it is not surprising that we found female AVM patients to have significantly higher TBF than males and that a trend toward decreasing flow was noted with advancing age. A significant difference in the distribution of TBF was apparent in patients who had suffered hemorrhagic complications of their AVMs. Most bleeding episodes had occurred within 3 months, but none more recently than 3 weeks, prior to the rCBF study. It is possible that persistent tissue abnormalities and perhaps alterations in cerebral perfusion pressure depress TBF values for protracted periods after ICH. Simple mass effect does not seem to be an acceptable explanation for this finding, since only eight of the 30 patients with $\mathrm{ICH}$ had residual intracerebral hematomas larger than $2 \mathrm{~cm}$ in diameter at the time of the rCBF study. Only three of those eight patients had TBF of less than $70 \mathrm{ml} / 100 \mathrm{gm} / \mathrm{min}$. A definite trend toward higher TBF values in patients with seizure disorders argues against ischemia as a cause of the seizures, ${ }^{10)}$ although regions of hypoperfusion were detected in all patients and may have been associated with focal ischemia.

The low-resistance nature of the vascular shunt is thought to be responsible for the chronic compensatory vasodilation and ultimate hypoperfusion of adjacent brain tissue. ${ }^{22}$ This hypoperfusion in conjunction with decreased metabolite delivery due to excessive venous pressure ${ }^{14}$ may explain the relatively common clinical presentation of progressive neurological deficit in patients found to harbor AVMs in certain brain regions. The lack of correlation in our data between TBF and the presence of progressive neurological deficits may be explained by the fact that TBF was calculated as the average of right and left hemispheric flow. Although each patient in this series did have an ipsilateral region of hypoperfusion, the use of hemispheric flow values may have failed to selectively identify significant ischemia in eloquent brain regions. These quantitative "steal" data will be presented in a separate manuscript. ${ }^{2)}$

Large, high-flow AVMs are considered to predispose to autoregulatory and hyperemic crises following resection or embolization of the shunt. ${ }^{13,14,22,23,26)}$ The relationship between TBF and AVM size in this series suggests that the magnitude of flow itself in large malformations may play a role in overwhelming the cerebral autoregulatory capacity. When patients who developed hyperemic complications following surgery were evaluated independently, however, no clear relationship with the magnitude of TBF emerged. Indirect measures of size in this series, including the number of major vessels involved in the feeding system, had no significant relationship to TBF values, nor did the sum of the diameters of all angiographically visible feeding arteries. The outcome following resection did appear to be influenced by TBF, since patients with lower preoperative $\mathrm{TBF}$ values tended to have unfavorable outcomes $(p=0.16)$.

Further data analysis is underway to determine if characteristics of hand-drawn regions of hypoperfusion or the integrity of vasoreactive properties in surrounding tissues are predictive of surgical complications. SPECT is an accurate, noninvasive means of assessing a variety of hemodynamic derangements associated with AVMs and their potential modification with treatment.

In summary, the important findings of this study were: 1) Females had higher TBF than males ( $p<$ $0.05)$; 2) TBF decreased with advancing age ( $\mathrm{p}=$ $0.14)$; 3) ICH was associated with lower TBF (p < $0.05)$; 4) TBF was higher in large than in small AVMs $(\mathrm{p}<0.05)$; and 5 ) Decreased TBF was associated with an unfavorable outcome $(\mathrm{p}=0.16)$.

\section{Acknowledgments}

The authors greatly appreciate the advice and support of Dr. Duke S. Samson in the planning of these studies. We are also indebted to Mrs. Vicki Rankin and Leticia Molina for their efforts in the preparation of this manuscript. 


\section{References}

1) Barnett GH, Little JR, Ebrahim ZY, Jones SC, Friel HT: Cerebral circulation during arteriovenous malformation operation. Neurosurgery 20: $836-842$, 1987

2) Batjer HH, Devous MD, Seibert GB, Purdy PD, Ajmani $A K$, Delarosa $M$, Bonte $F J$ : Intracranial arteriovenous malformation: Relationship between clinical and radiographic factors and ipsilateral steal severity. Neurosurgery 23: 322-328, 1988

3) Celsis P, Goldman T, Henricksen L, Lassen NA: A method for calculating regional cerebral blood flow measured by dynamic single-photon emission tomography of inert gas concentrations. $J$ Comput Assist Tomogr 5: 641-645, 1981

4) Deutsch G: Blood flow changes in arteriovenous malformation during behavioral activation. $A n n$ Neurol 13: 38-43, 1983

5) Devous MD, Stokely EM, Chehabi HH, Bonte FJ: Normal distribution of regional cerebral blood flow measured by dynamic single-photon emission computed tomography. J Cereb Blood Flow Metabol 6: 95-104, 1986

6) Haggendal E, Ingvar DH, Lassen NA, Nillson NJ, Horlen G, Wickbom I, Zwetnow N: Pre- and postoperative measurements of regional cerebral blood flow in three cases of intracranial arteriovenous aneurysms. $J$ Neurosurg 22: 1-6, 1965

7) Homan RW, Devous MD, Stokely EM, Bonte FJ: Quantification of intracerebral steal in patients with arteriovenous malformation. Arch Neurol 43: 779785,1986

8) Kanno I, Lassen NA: Two methods for calculating regional cerebral blood flow from emission computed tomography of inert gas concentrations. J Comput Assist Tomogr 3: 71-76, 1979

9) Lindegaard KF, Grolimund P, Aaslid R, Nornes H: Evaluation of cerebral AVM's using transcranial Doppler ultrasound. I Neurosurg 65: 335-344, 1986

10) Luessenhop AJ: Natural history of cerebral arteriovenous malformations, in Wilson CB, Stein BM (eds): Intracranial Arteriovenous Malformations. Baltimore, Williams \& Wilkins, 1984, pp 12-23

11) Menon D, Weir B: Evaluation of cerebral blood flow in arteriovenous malformations by the xenon-133 inhalation method. Can J Neurol Sci 6: 411-416, 1979

12) Norlen G: Arteriovenous aneurysms of the brain. Report of 10 cases of total removal of the lesion. $J$ Neurosurg 6: 475-494, 1949

13) Nornes H: Quantification of altered hemodynamics, in Wilson CB, Stein BM (eds): Intracranial Arteriovenous Malformations. Baltimore, Williams \& Wilkins, 1984, pp 32-43

14) Nornes $H$, Grip A: Hemodynamic aspects of cerebral arteriovenous malformations. $J$ Neurosurg 53: 456464,1980

15) Okabe T, Meyer JS, Okayasu H, Harper R, Rose J,
Grossman RG, Centeno R, Tachibana H, Lee YY: Xenon-enhanced CT CBF measurements in cerebral AVM's before and after excision. $J$ Neurosurg 59: 21-31, 1983

16) Pertuiset B, Ancri D, Arthuis F, Basset JY, Fusciardi J, Nakano H: Shunt induced haemodynamic disturbances in supratentorial arteriovenous malformations. J Neuroradiol 12: 165-178, 1985

17) Rosenblum BR, Bonner RF, Oldfield EH: Intraoperative measurement of cortical blood flow adjacent to cerebral AVM using laser Doppler velocimetry. $J$ Neurosurg 66: 396-399, 1987

18) Schwartz A, Hennerici M: Noninvasive transcranial Doppler ultrasound in intracranial angiomas. Neurology (NY) 36: 626-635, 1986

19) Shenkin HA, Spitz EB, Grant FC, Kety SS: Physiologic studies of arteriovenous anomalies of the brain. $J$ Neurosurg 5: 165-172, 1948

20) Smith GT, Stokely EM, Lewis MH, Devous MD, Bonte FJ: An error analysis of the double-integral method for calculating brain blood perfusion from inert gas clearance data. $J$ Cereb Blood Flow Metabol 4: $61-67,1984$

21) Spetzler RF, Martin NA: A proposed grading system for arteriovenous malformations. $J$ Neurosurg 65 : 476-483, 1986

22) Spetzler RF, Selman WR: Pathophysiology of cerebral ischemia accompanying arteriovenous malformations, in Wilson CB, Stein BM (eds): Intracranial Arteriovenous Malformations. Baltimore, Williams \& Wilkins, 1984, pp 24-31

23) Spetzler RF, Wilson CB, Weinstein $P$, Mehdorn $M$, Townsend J, Telles D: Normal perfusion pressure breakthrough theory. Clin Neurosurg 25: 651-672, 1978

24) Stokely E, Sveinsdotter E, Lassen N, Rommer P: A single-photon dynamic computer assisted tomograph (DCAT) for imaging brain function in multiple cross sections. J Comput Assist Tomogr 4: 230-240, 1980

25) Takeuchi $S$, Kikuchi $H$, Karasawa J, Naruo $Y$, Hashimoto K, Nishimura T, Kozuka T, Hayashi M: Cerebral hemodynamics in arteriovenous malformations: Evaluation by single-photon emission CT. AJNR 8: 193-197, 1987

26) Wilson $\mathrm{CB}, \mathrm{U}$ HS, Domingue $\mathrm{J}$ : Microsurgical treatment of intracranial vascular malformations. $J$ Neurosurg 51: 446-454, 1979

27) Yamada S: Arteriovenous malformations in the functional area: Surgical treatment and regional cerebral blood flow. Neurol Res 4: 283-322, 1982

Address reprint requests to: H.H. Batjer, M.D., Division of Neurological Surgery, the University of Texas Southwestern Medical Center at Dallas, 5323 Harry Hines Boulevard, Dallas, Texas 75235-8855, U.S.A. 